\title{
Enhancement of bioenergy production from organic wastes by two-stage anaerobic hydrogen and methane production process
}

\author{
Luo, Gang; Xie, Li; Zhou, Qi; Angelidaki, Irini
}

Published in:

Bioresource Technology

Link to article, DOI:

10.1016/j.biortech.2011.02.012

Publication date:

2011

Link back to DTU Orbit

Citation (APA):

Luo, G., Xie, L., Zhou, Q., \& Angelidaki, I. (2011). Enhancement of bioenergy production from organic wastes by two-stage anaerobic hydrogen and methane production process. Bioresource Technology, 102(18), 8700-8706. https://doi.org/10.1016/j.biortech.2011.02.012

\section{General rights}

Copyright and moral rights for the publications made accessible in the public portal are retained by the authors and/or other copyright owners and it is a condition of accessing publications that users recognise and abide by the legal requirements associated with these rights.

- Users may download and print one copy of any publication from the public portal for the purpose of private study or research.

- You may not further distribute the material or use it for any profit-making activity or commercial gain

- You may freely distribute the URL identifying the publication in the public portal 
1 Enhancement of bioenergy production from organic wastes

2 by two-stage anaerobic hydrogen and methane production

\section{3 process}

4

5 Gang Luo $^{\mathrm{a}, \mathrm{b}}$, Li Xie ${ }^{\mathrm{b}}$, Qi Zhou ${ }^{\mathrm{b}}$, and Irini Angelidaki ${ }^{\mathrm{a}^{*}}$

6

$7 \quad{ }^{a}$ Department of Environmental Engineering, Technical University of Denmark,

8 DK-2800, Kgs Lyngby, Denmark

$9 \quad{ }^{a}$ Key Laboratory of Yangtze River Water Environment, State Key Laboratory of

10 Pollution Control and Resources Reuse, College of Environmental Science and

11 Engineering, Tongji University, Shanghai 200092, PR China

12

13

14 * Corresponding author: e-mail: iria@env.dtu.dk (I. Angelidaki), Tel: +45 45251429

15 Fax: +45 45932850 . 
Abstract:

The present study investigated a two-stage anaerobic hydrogen and methane process

18 for increasing bioenergy production from organic wastes. A two-stage process with hydraulic retention time (HRT) 3d for hydrogen reactor and 12d for methane reactor, obtained 11\% higher energy compared to a single-stage methanogenic process (HRT

21 15d) under organic loading rate (OLR) $3 \mathrm{gVS} /(\mathrm{L} \cdot \mathrm{d})$. The two-stage process was still stable when the OLR was increased to $4.5 \mathrm{gVS} /(\mathrm{L} \cdot \mathrm{d})$, while the single-stage process failed. The study further revealed that by changing the $\mathrm{HRT}_{\text {hydrogen }}: \mathrm{HRT}_{\text {methane }}$ ratio of the two-stage process from 3:12 to $1: 14,6.7 \%$, more energy could be obtained. Microbial community analysis indicated the dominant bacterial species were different in the hydrogen reactors (Thermoanaerobacterium thermosaccharolyticum-like species) and methane reactors (Clostridium thermocellum-like species). The changes of substrates and HRT did not change the dominant species. The archaeal community structures in methane reactors were similar both in single- and two- stage reactors, with acetoclastic methanogens Methanosarcina acetivorans-like organisms as the dominant species.

Key words: anaerobic digestion, hydrogen, methane, two-stage process 


\section{Introduction}

Hydrogen produced from biomass is renewable energy carrier. Among the various hydrogen production methods, dark fermentation of organic wastes seems to be the most promising and environmentally friendly method. The feasibility of such method has been demonstrated in several studies (Cai et al., 2004; Liu et al., 2006). However, the main obstacles in such process are the lower hydrogen yield ( $<4 \mathrm{~mol} \mathrm{H}_{2} / \mathrm{mol}^{2}$ Glucose) and higher residual organic concentration in the effluent (Xie et al., 2008).

The effluents of the dark fermentation process contain mainly acetate, propionate, butyrate etc., which should be further utilized to increase the total energy recovery efficiency.

Combined hydrogen and methane production in a two-stage process is a concept which has been developed in recent years (Kyazze et al., 2007; Liu et al., 2006; Ueno et al., 2007). It is similar with the traditional two-phase process that separates hydrolysis/acidogenesis and methanogenesis, and optimizes each process separately, leading to a larger overall reaction rate and biogas yield (Fox and Pohland, 1994). The main difference is that hydrogen is retrieved in the first stage of the two-stage process for hydrogen and methane production. The co-production of hydrogen and methane is more promising from an energy perspective. Liu et al. (2006) has demonstrated that more methane could be obtained by two-stage hydrogen and methane process. Also, the mixture of hydrogen and methane has many advantages than methane alone, which could improve the efficiency of the methane combustion motors and decrease the emissions of $\mathrm{CO}_{2}$ and $\mathrm{CO}$ (Akansu et al., 2004). Several studies have been conducted to investigate the hydrogen and methane production in the two-stage process. However, they mainly focused on the optimization of hydrogen and methane reactors individually (Antonopoulou et al., 2008; Venetsaneas et al., 2009). It is 
necessary to optimize the whole system for higher total energy production. In addition, the mechanisms involved in the two-stage process and the microbial community structures have not been investigated and clarified, which is crucial for better understanding of the process.

Concerns about instability of fossil fuels supply, limits on fossil fuel reserves and not least environmental pollutions and climate changes, have brought new lights in utilization of biomass in biorefinery concepts, where biomass is used as feedstock instead of fossil fuels for production bio-based fuels, chemicals, solvents etc. by biological conversion processes. We have proposed a novel biorefinery concept based on rapeseed plant (Luo et al., 2010a), where the oil seed is used for biodiesel production and the straw is used for bioethanol production. From this process several effluent sub-streams are generated, which need to be utilized for full utilization of the organic matter. Rapeseed cake and glycerol are the by-products in the biodiesel process, and the search for proper disposal methods is still going on (Thamsiriroj and Murphy, 2010). Stillage is the wastewater from bioethanol production process and it contains high concentrations of degradable organic pollutants. The utilization of the above three sub-streams for bioenergy production is necessary from environmental protection and sustainability viewpoints.

Therefore, in the present study we investigated and compared different configurations of two-stage process for hydrogen and methane production from the above organic streams and studied the role of the hydrogen reactor in the whole system. Single-stage process for methane production was operated as control. Finally, the microbial communities in different reactors and operation conditions were identified. 


\section{Material and methods}

\subsection{Feedstocks and inoculum}

The stillage used in this study was obtained from an ethanol plant in Lithuania.

Rapeseed cake and glycerol waste from the biodiesel production process were obtained from a local company (Emmelev). The samples were stored at $-20{ }^{\circ} \mathrm{C}$. The substrates were thawed and kept at $4{ }^{\circ} \mathrm{C}$ for $2-3$ days before usage. $24 \mathrm{~g}$ cake and $2 \mathrm{ml}$ glycerol was added to $1 \mathrm{~L}$ stillage based on the biorefinery concept described in (Luo et al., 2010a). The characteristics of the three wastes and their mixture are shown in Table 1. Thermophilic anaerobic digested manure (Biogas plant, Snertinge, Denmark) was used as inoculum for both hydrogen and methane production.

\subsection{Reactor set-up and operations}

Two-stage (hydrogen and methane) operation was compared with single-stage methane operation. The hydrogen reactor $(\mathrm{H})$ was a 2 L continuously stirred tank reactor (CSTR) with working volume $1.2 \mathrm{~L}$, while the methane reactors (M) was $4.5 \mathrm{~L}$ CSTR with working volume $3.5 \mathrm{~L}$. The configurations of all the reactors were similar and described in Boe et al. (2009). All reactors were stirred four times (3 min for each time) per hour throughout the experiment by motor mixer with a timer. The substrates were fed to all the reactors four times per day using peristaltic pump with timer control. Before feeding, $8 \mathrm{~g} / \mathrm{L} \mathrm{NaHCO}_{3}$ was added to the stillage or mixture to adjust the $\mathrm{pH}$ to around 6. The two-stage process was tested at two different distributions of HRT between hydrogen and methane reactors. The first HRT distribution tested was 3:12 i.e. the HRT for the hydrogen reactor was 3 days (H3) and the HRT for the methane reactor was 12 days (M12), while the second HRT distribution was 1:14, i.e. 1 day HRT for the hydrogen reactor (H1) and 14 days HRT for the methane reactor (M14). A single-stage methane reactor was operated at HRT of 15 days (M15). All 
experiments were conducted at $55{ }^{\circ} \mathrm{C}$. The operation data of the reactors were shown in Table 2.

For the first two-stage experiment, the HRT distribution of 3:12 was tested. The reactor H3 was initially filled with $200 \mathrm{ml}$ inoculum, $500 \mathrm{ml}$ stillage and diluted by water to final volume $1.2 \mathrm{~L}$. The initial $\mathrm{pH}$ of the mixture was adjusted to 6 by $\mathrm{NaOH}$. After the hydrogen production ceased, the reactor was fed semi-continuously. For M12 and M15, the reactors were initially filled with $3.2 \mathrm{~L}$ inoculum and $300 \mathrm{ml}$ stillage. After the methane production ceased, the reactors were also fed semi-continuously. The effluent of H3 was fed to M12. Initially, H3 and M15 were fed with only raw stillage to get a successful start-up at relatively low OLR. After steady-states were achieved, the mixture was fed to the reactors (From day 46 to day 118). The steady-state in this study was defined as a stable biogas production with daily variation of lower than $10 \%$.

From day 75 to day 126, the second two-stage experiment with the same total HRT $15 \mathrm{~d}$, but HRT distribution of 1:14 between hydrogen and methane reactors was started. The reactors were the same as those used in the experiment with HRT distribution of 3:12, but with different feeding flow rates. The inocula for H1 and M14 were from the effluents of H3 and M12, respectively. The reactors were directly fed with the mixture of stillage, cake and glycerol.

\subsection{Specific methanogenic activity (SMA) tests}

Batch experiments for estimation of the specific methanogenic activity (SMA) on a specific substrate were carried out when steady-states were achieved in the methane reactors. $40 \mathrm{~mL}$ basal anaerobic (BA) medium (Karakashev et al., 2005) was dispensed anaerobically in $100 \mathrm{~mL}$ serum bottles. The media were supplemented with different substrates-acetate (20 mM), propionate (10 mM), butyrate (10 mM), 
hydrogen/carbon dioxide (80/20) under 1 atm, and glucose (10 mM). After addition of vitamin solution and $\mathrm{Na}_{2} \mathrm{~S} .9 \mathrm{H}_{2} \mathrm{O}$ as a reducing agent the medium was inoculated with $10 \mathrm{~mL}$ fresh samples from each reactor and incubated in respective temperature of inoculums. Bottles with BA medium and inocula only, but without substrates, were used as controls (blanks). All the tests were prepared in duplicates. The SMA was calculated as the initial, linear methane accumulation rate divided by the biomass VS content in each series.

\subsection{Microbial community analysis}

Bacterial communities in both hydrogen and methane reactors at steady-states were analyzed. Genomic DNA extraction, PCR-DGGE and sequencing were made as previously described (Zhao et al., 2009). Archaeal communities in methane reactors at steady-states were also analyzed. The procedure was similar with bacterial community analysis. The only differences were the PCR primers and amplification procedures. For the first amplification, primers 1492-r and 109-f were used and the thermal cycling program was as follows: $94^{\circ} \mathrm{C}$ for 2 min,35 cycles of three steps: $94{ }^{\circ} \mathrm{C}$ for 1 min, $51^{\circ} \mathrm{C}$ for $1 \mathrm{~min}$, and $72{ }^{\circ} \mathrm{C}$ for $1 \mathrm{~min}$, followed by a final step at $72{ }^{\circ} \mathrm{C}$ for 10 min; For the second amplification, primers 515-r and 109(T)-f were used and the thermal cycling program was as follows: $94^{\circ} \mathrm{C}$ for 3 min, 34 cycles of three steps: $94{ }^{\circ} \mathrm{C}$ for $1 \mathrm{~min}, 53{ }^{\circ} \mathrm{C}$ for $1 \mathrm{~min}$, and $72{ }^{\circ} \mathrm{C}$ for $2 \mathrm{~min}$, followed by a final step at $72{ }^{\circ} \mathrm{C}$ for $10 \mathrm{~min}$. All bands from DGGE were sequenced and identified by comparing the 16S rRNA gene sequences with DNA sequences in the National Centre for Biotechnology Information (NCBI) database using the BLAST algorithm.

\subsection{Analytical methods}

Total and soluble chemical oxygen demand (TCOD and SCOD), Total solids (TS), volatile solids (VS), ash content, suspended solids (SS), volatile suspended solids 
(VSS), ammonia and total nitrogen were determined according to the Standard Methods (APHA, 1995). SCOD samples were filtered through glass fiber paper (U90 mm, GF50, Schleicher \& Schuell). Lipid extraction was carried out by Soxhlet Method (APHA, 1995). Protein and carbohydrate were calculated according to (Kaparaju et al., 2009). The concentrations of ethanol, acetate, butyrate, propionate were determined by gas chromatograph (GC) (Hewlett Packard, HP5890 series II) equipped with a flame ionization detector and HP FFAP column $(30 \mathrm{~m} \times 0.53 \mathrm{~mm} \times 1.0$ $\mu \mathrm{m})$. Hydrogen was analyzed by GC-TCD fitted with a $4.5 \mathrm{~m} \times 3 \mathrm{~mm}$ s-m stainless column packed with Molsieve SA (10/80). Methane was analyzed with GC-TCD fitted with parallel column of $1.1 \mathrm{~m} \times 3 / 16$ "Molsieve 137 and $0.7 \mathrm{~m} \times 1 / 4$ " chromosorb 108. Detailed information about the operation conditions of above GC and HPLC was described in (Luo et al. 2010a). Analysis of variance (ANOVA) at 0.05 level was used to analyze the data.

\section{Results and discussion}

\subsection{Reactor Performances}

The two-stage (H3+M12) and single-stage reactors (M15) were started up at the same time. The monitoring profiles of hydrogen, methane, $\mathrm{pH}$, volatile fatty acids (VFA) are shown in Fig 1 and Fig 2, and the overall performances of the reactors at steady-states are summarized in Table 3. Initially (day 1 to 45), the reactors were fed with stillage alone. For the two-stage process, hydrogen was produced immediately and the hydrogen reactor stabilized after about 7 days (Fig 2 A). The hydrogen yield was $69 \mathrm{ml}-\mathrm{H}_{2} / \mathrm{gVS}$, which was comparable with $76 \mathrm{ml}-\mathrm{H}_{2} / \mathrm{gVS}$ from cassava stillage in our previous study (Luo et al., 2010b). The methane production rate increased initially slowly, while rapid increase was found after about 6 days (Fig 2 C). After 15 
days, the methane production was relatively stable with methane production rate around $1300 \mathrm{ml}-\mathrm{CH}_{4} /(\mathrm{L} \cdot \mathrm{d})$. Similar trend for methane production was observed in single-stage process (M15). However, the methane production rate in M15 was about

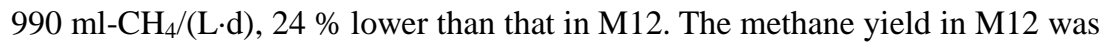
calculated as 348 ml-CH $4 /$ gVS, which was significantly $(p=0.008<0.05)$ higher than

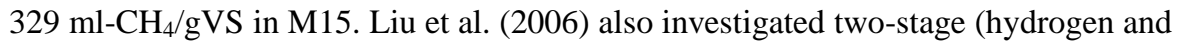
methane) and single-stage (methane) processes for treatment of household solid waste and found $21 \%$ enhancement of methane yield in the two-stage process. In their study the HRT for methane reactors in both systems were $15 \mathrm{~d}$. In our study, the enhancement was only about $5.7 \%$, which could be due to the shorter HRT (12 days) in the two-stage process. Considering the additional hydrogen production, the total energy recovery (Table 3) in the two-stage process could be $11 \%$ higher than that in single-stage process. The higher energy recovery in the two-stage process was also consistent with the lower TCOD and VS concentration in the effluent (Table 3). VFA and ethanol were detected in both M12 and M15 with propionate as the dominant metabolite, which indicated the incomplete removal of intermediate metabolites.

The addition of cake and glycerol from day 44 did not lead to the increase of hydrogen production compared to stillage alone (Fig 2 A). The hydrogen yield of the mixture was only $48 \mathrm{ml}-\mathrm{H}_{2} / \mathrm{gVS}$. For M12, the methane production rate increased

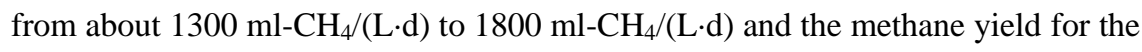
mixture was about $320 \mathrm{ml}-\mathrm{CH}_{4} / \mathrm{gVS}$. The results indicated that cake and glycerol could successfully be utilized for methane production. Rapeseed cake is lignocellulosic material (Egues et al., 2010) and the carbohydrate was not easily accessible for hydrogen production at the short HRT (3 d) applied, but the longer HRT (12 d) in subsequent methane reactor led to the solubilization of organics for methane 
production. Though studies have demonstrated the feasibility of hydrogen production from glycerol (Selembo et al., 2009), the hydrogen yield was very low (0.28 mol- $\mathrm{H}_{2} / \mathrm{mol}$ glycerol). The pure glycerol contained in the glycerol waste in our study was only $33 \%$, and the glycerol concentration in the mixture (2 $\mathrm{ml} / \mathrm{L})$ was also low, which could not lead to measurable increase of hydrogen production (only 15 ml- $\left.\mathrm{H}_{2} /(\mathrm{L} \cdot \mathrm{d})\right)$. For the single-stage reactor M15, the methane production ceased after about 30 days due to the low $\mathrm{pH}(<6)$, resulted from the accumulation of VFA especially acetate and butyrate. This could be attributed to the increase of OLR (from to $3 \mathrm{gVS} /(\mathrm{L} \cdot \mathrm{d})$ to $4.5 \mathrm{gVS} /(\mathrm{L} \cdot \mathrm{d}))$ by changing the reactor influent from stillage to the mixture of stillage, cake and glycerol. The results further demonstrated that the two-stage process could withstand higher OLR than single-stage process. In M12, propionate was still the dominant metabolite. The acetate concentration increased from $6.3 \mathrm{mM}$ (stillage as substrate) to $19.3 \mathrm{mM}$ (mixture as substrate), but it did not inhibit the methane production.

From day 77, another configuration of two-stage process (H1+M14) was started up. The HRT in the hydrogen reactor was reduced to $1 \mathrm{~d}$, while that for the methane reactor was increased to $14 \mathrm{~d}$. Both reactors reached steady-state quickly because the inocula were acclimated to the substrate (Fig 3). The hydrogen yield (40 ml- $\mathrm{H}_{2} / \mathrm{gVS}$ ) in $\mathrm{H} 1$ was $17 \%(\mathrm{p}=0.006<0.05)$ lower than that in $\mathrm{H} 3$, while the methane yield in M14 (344 ml-CH $4 / \mathrm{gVS})$ was $7.5 \%(\mathrm{p}=0.005<0.05)$ higher than that in M12. In our study, the hydrogen production was mainly associated with butyrate production (Fig 3 B), which is in accordance with previous studies focusing on thermophilic hydrogen production (Akutsu et al., 2009; Ueno et al., 2007). The decreased hydrogen yield in H1 was coincident with decreased butyrate concentration compared to H3. The total energy recovery in $\mathrm{H} 1+\mathrm{M} 14$ was $12.7 \mathrm{KJ} / \mathrm{gVS}$, which was $6.7 \%(\mathrm{p}=0.01<0.05)$ 
higher compared to H3+M12. It is worth noticing that the acetate concentration in M14 decreased to $8.7 \mathrm{mM}$, and was significantly lower than that in M12. However, the propionate concentration was still at the same level. The different HRT distribution in hydrogen and methane reactors was shown to significantly affect the production of hydrogen and methane, as well as the total energy recovery. Under the same total HRT, the short HRT in the hydrogen reactor was enough to maintain the stability of the two-stage system, while the longer HRT in the methane reactor would lead to the improved performance of the two-stage system. It is the first time to reveal the importance of HRT distribution between hydrogen and methane reactors on total energy production.

In all cases, the energy from hydrogen in the two-stage process accounted for lower than $6 \%$ of the total energy recovery (Table 3). The results were consistent with Zhu et al. (2008), who studied the hydrogen and methane production from potato waste and found only about $5 \%$ of the energy was from hydrogen. Theoretically, in the two-stage process, $1 \mathrm{~mol}$ glucose could be converted to $4 \mathrm{~mol}$ hydrogen and $2 \mathrm{~mol}$ methane $\left(\mathrm{C}_{6} \mathrm{H}_{12} \mathrm{O}_{6}+2 \mathrm{H}_{2} \mathrm{O} \rightarrow 2 \mathrm{CH}_{3} \mathrm{COOH}+2 \mathrm{CO}_{2}+4 \mathrm{H}_{2} ; 2 \mathrm{CH}_{3} \mathrm{COOH} \rightarrow 2 \mathrm{CH}_{4}+2 \mathrm{CO}_{2}\right)$ (Xie et al., 2008), which means the energy from hydrogen could be accounted for $37.6 \%$ of the total energy recovery. Nevertheless, $4 \mathrm{~mol}-\mathrm{H}_{2} / \mathrm{mol}$ glucose can not be achieved in practice, considering production of several other metabolites than acetate, such as, butyrate and propionate as well as production of cell biomass (Ueno et al., 2007). In addition, the actual organic wastes may also contain protein and lipids besides carbohydrate, which are not suitable substrates for hydrogen production, but are good for methane production. In our study, the dominant metabolite for hydrogen production was butyrate (Table 3). Additionally, the substrate contains certain amounts of protein and lipids besides carbohydrates (Table 1) which finally led to the 
lower energy recovery as hydrogen compared to the theoretically calculated value.

Though the contribution of hydrogen to total energy is minor, it was crucial to maintain the stability of the subsequent methane reactor. Our results also revealed that optimization of hydrogen and methane reactor individually is not proper since methane is the main energy carrier. By appropriate adjustment of reactor configuration of the two-stage process (i.e. different HRT distribution between hydrogen and methane reactor), the total energy in the system could be enhanced. Therefore, further study should be focused on the optimization of the total energy production in the two-stage system and pilot-scale reactors should be investigated to speed up the application of two-stage process. It needs to be pointed out that though the two-stage process could obtain more energy and achieve higher OLR compared with single-stage process, the operation and control of such process is complicated which should be carefully considered before industrial application.

For traditional two-phase anaerobic process, the higher biogas production was attributed to enhanced hydrolysis of the substrate in acidogenic reactor and improved activity of methanogens in the methanogenic reactor (Fox and Poland, 1994).

However, it seems that the improved performance of two-stage process in our study was not due to the enhanced hydrolysis of substrate, because there was no significant difference $(\mathrm{p}=0.74>0.05$ ) between effluent VSS in both single-stage and two-stage processes (Stillage as substrate) (Table 3). The short HRT (3d) in hydrogen reactor may be not enough to significantly enhance the hydrolysis of the whole process, but it is suitable for hydrogen production. The reason for higher biogas production in two-stage process should be attributed to the enhanced methanogenic activities in the methane reactors, which was demonstrated by SMA tests in subsequent section. Another possible reason for the improved biogas production was due to a serial 
operation minimizing the loss of relatively "fresh feed" out of the reactor due to “short-circuiting”, occurring in single-stage fully mixed reactors.

\subsection{SMA}

The SMA results of the sludge biomass from different methane reactors on various substrates are shown in Table 4. The degradation rates for glucose, acetate, and butyrate in M12 of the two-stage process were much higher than that in M15 when stillage was used as substrate. This could be the reason for the better performance of the two-stage process. When mixture was used as substrate, the degradation rates for glucose, acetate, and butyrate in M12 of the two-stage processes still maintained at a high level, which demonstrated that the higher OLR did not inhibit the biogas process. For M14 (mixture as substrate), the degradation rate for acetate was much higher than that for M12. The result was consistent with the lower acetate concentration and higher energy recovery in M14. Conclusively, the hydrogen reactors played an important role to maintain a stable and efficient gasification process. Our results are consistent with previous investigations of two-phase process, where it was concluded that the separation of acidogenesis and methanogenesis favored the methanogenesis in the second-phase (Fox and Pohland, 1994). In our study the improved performance of the two-stage system was more attributed to the enhanced methanogenic activities and not to enhanced hydrolytic/acidogenic activity. On the contrary, previous investigations on two-phase process focused on optimizing the conditions for hydrolysis/acidogenesis in the first stage and not in hydrogen production (Elefsiniotis et al., 1996; He et al., 2005).

The SMA tests also showed that the degradation rates for propionate were very low in all cases, which was consistent with the high propionate concentrations in all the 
methane reactors. Low propionate degradation rate has been attributed to high organic loading, VFA inhibition and lack of macro- and micro-nutrients in the substrates (Cresson et al., 2006; Kida et al., 1993; van Lier et al., 1993). Anaerobic digestion in single-stage CSTR with OLR between 2.5 and $5 \mathrm{gVS} /(\mathrm{L} \cdot \mathrm{d})$ have been reported to work stably, without propionate accumulation (Liu et al., 2006; Zhu et al., 2008). In our study, the OLR was initially $3 \mathrm{gVS} /(\mathrm{L} \cdot \mathrm{d})$ and subsequently increased to 4.5 $\mathrm{gVS} /(\mathrm{L} \cdot \mathrm{d})$, which was within the range for good propionate degradation. Furthermore, acetate and butyrate concentrations in our study were not high enough to inhibit degradation of propionate (Van lier et al., 1993). A possible explanation for accumulation of propionate could be the lack of some macro- and micro-nutrients in the substrate. Agler et al. (2008) reported that VFA accumulation was observed even when the OLR was only around $1.2 \mathrm{gVS} /(\mathrm{L} \cdot \mathrm{d})$ when using anaerobic sequencing batch reactor for the treatment of stillage. Addition of Co $(20 \mathrm{mg} / \mathrm{L})$ resulted in decrease of VFA. Moreover, the OLR could be increased to as high as $7.5 \mathrm{gVS} /(\mathrm{L} \cdot \mathrm{d})$ without the process to be disturbed. We also analyzed for the metal ions in the stillage and mixture, and found both Co was below detection limits ( $<7 \mathrm{ug} / \mathrm{L})$, which might be the reason for accumulation of propionate. Though the propionate concentration was higher in our study, it did not apparently affect the process stability and the methane yield was still very high (>300 ml-CH$/$ gVS). Similarly, Wiegant et al. (1985) found high propionate concentration (27-80 mM) under thermophilic condition, but the anaerobic process was still stable. Moreover, the effluent quality did not deteriorate with increasing loading rates from 17 to $98 \mathrm{kgCOD} /\left(\mathrm{m}^{3} \cdot \mathrm{d}\right)$ in UASB.

\subsection{Microbial communities}

DGGE was conducted to analyze the microbial communities in all the reactors and

Comment [r1]: I think van Lier is written with small $\mathrm{v}$ and not capital $\mathrm{V}$. Please check. 
the sequencing results were shown in Table 5. The bacterial communities in both hydrogen and methane reactors were shown in Fig 4. For hydrogen reactors (Lanes A, D, F), the bacterial communities included members affiliated within one phyla Firmicutes, and two unaffiliated bands (4 and 6). The change of substrate from stillage to mixture in $\mathrm{H} 3$ led to the appearance of another two weak bands 4 and 6 besides the dominant band 9. The decrease of HRT from 3d to 1d led to the significant shift of dominant bands from band 9 to bands 6, 8 and 11. It seems that HRT was an important parameter determining the relative composition of the microbial communities in the hydrogen reactor. Nevertheless, Thermoanaerobacterium thermosaccharolyticum was always the dominant species (band 8 and 9) even with different substrates and HRT, indicating this bacterium is robust and can grow well in a wide range of environmental conditions. T. thermosaccharolyticum can use glucose, starch, and sucrose for hydrogen production and the optimal growth was in the range pH 5-6 under thermophilic condition (O-Thong et al., 2008). T. thermosaccharolyticum was also reported as the dominant species in thermophilic hydrogen reactors from other study (Ahn et al., 2005).

For methane reactors, the phylogenetic affiliations of bacterial community converged within three phyla, Firmicutes, Proteobacteria, Actinobacteria, which were more diverse than the communities in hydrogen reactors. When stillage was used as substrate, the dominant species in M12 was only band 10, while bands 1 and 2 were also dominant species besides band 10 in M15 (Lanes B and C). It is obvious the bacterial communities were different in the methane reactors of two-stage and single-stage process, which also could explain the different performances of the two different systems. Band 1 showed $96 \%$ similarity to uncultured gamma proteobacterium and band 2 showed $95 \%$ similarity to uncultured pseudomonas sp., 
both of which were isolated from anaerobic activited sludge (unpublished data). Band 10 was related to Clostridium thermocellum, which could utilize carbohydrates to produce various metabolites (acetate, ethanol et al.) (Nochur et al., 1992). Band 10 was also dominant in M 12 and M 14 when mixture was used (Lanes E and G). Moreover, band 3 was closely related to Propionibacterium sp. (97\%), and this bacteria could utilized carbohydrate for propionate production (Schuppert et al., 1992). The higher propionate concentrations in all the methane reactors may be attributed to the above microorganism.

For methane reactors, the archaeal DGGE bands were similar at all conditions (Fig 5), which indicated archaeal community structures were not obviously affected by the changes of substrates and HRT. Although the relative dominance of microorganisms did not change, the concentration of microorganisms and their activities might have been altered, since DGGE is only a qualitative method. Therefore, the estimated increase of SMA of aceticlastic methanogenesis, could have been due to increase of aceticlastic biomass and activity in the reactors, and not to change of microorganism-types. The dominant band 3 showed $96 \%$ similarity to Methanosarcina acetivorans str. , which belonged to acetoclastic methanogens (Karakashev et al., 2005). Band 4 was also related to Methanosarcina species. Methanosarcina species were reported to be dominant at high acetate concentration (>1.2 mM) (Chu et al., 2010), and the results were consistent with the high acetate concentrations in all the methane reactors (Table 3). Band 1 and 2 were related to Methanoculleus species, which were responsible for hydrogenotrophic methanogenesis (Shin et al., 2010). The activities of hydrogenotrophic methanogens were also demonstrated by SMA tests and all the sludge biomass from different methane reactors exhibited obvious degradation rate of hydrogen ( $>20$ 
$\left.\mathrm{ml}-\mathrm{CH}_{4} /(\mathrm{gVS} \cdot \mathrm{d})\right)$.

\section{Conclusions}

The two-stage hydrogen and methane process could obtain $11 \%$ more energy compared to single-stage process under OLR of $3 \mathrm{gVS} /(\mathrm{L} \cdot \mathrm{d})$. The increase of OLR to $4.5 \mathrm{gVS} /(\mathrm{L} \cdot \mathrm{d})$ led to the break down of the single-stage process, while the two-stage process could work stably. The study also revealed that by proper adjustment of HRT distribution between hydrogen and methane reactors, more energy could be obtained. Microbial community analysis showed the dominant bacteria were always related to $T$. thermosaccharolyticum in hydrogen reactors and C. thermocellum in methane reactors. The acetotrophic methanogens Methanosarcina acetivorans-like organisms were the dominant archaeal species in methane reactors.

\section{Acknowledgements}

We thank Dimitar Karakashev, Yifeng Zhang and Sompong O-Thong for advice on molecular biotechnology work and also thank Hector Garcia for his technical support during the experiments. This study received support from Danish Agency for Science, Technology and Innovation under Bio REF. Project No. 2104-06-0004. This work was also supported by the Foundation of Key Laboratory of Yangtze River Water Environment, Ministry of Education (Tongji University), China (No. YRWEY1003) and the Bayer Sustainable Development Foundation. Gang Luo would like to thank for the financial support from China Scholarship Council and also the Shanghai Tongji Gao Tingyao Environmental Science \& Technology Development Foundation.

\section{References:}


Agler, M.T., Garcia, M.L., Lee, E.S., Schlicher, M., Angenent, L.T., 2008.

Thermophilic anaerobic digestion to increase the net energy balance of corn grain ethanol. Environ. Sci. Technol. 42, 6723-6729.

Ahn, Y., Park, E.J., Oh, Y.K., Park, S., Webster, G., Weightman, A.J., 2005. Blofilm microbial community of a thermophilic trickling biofilter used for continuous biohydrogen production. FEMS Microbiol. Lett. 249, 31-38.

Akansu, S.O., Dulger, Z., Kahraman, N., Veziroglu, T.N., 2004. Internal combustion engines fueled by natural gas - hydrogen mixtures. Int. J. Hydrogen Energy 29, 1527-1539.

Akutsu, Y., Lee, D.Y., Chi, Y.Z., Li, Y.Y., Harada, H., Yu, H.Q., 2009. Thermophilic fermentative hydrogen production from starch-wastewater with bio-granules. Int. J. Hydrogen Energy 34, 5061-5071.

Antonopoulou, G., Stamatelatou, K., Venetsaneas, N., Kornaros, M., Lyberatos, G., 008. iohydrogen and methane production from cheese whey in a two-stage anaerobic process. Ind. Eng. Chem. Res. 47, 5227-5233.

APHA, 1995. Standard methods for the examination of water and wastewater, 19th ed. New York, USA: American Public Health Association.

Boe, K., Karakashev, D., Trably, E., Angelidaki, I., 2009. Effect of post-digestion temperature on serial CSTR biogas reactor performance. Water Res. 43, 669-676.

Cai, M.L., Liu, J.X., Wei, Y.S., 2004. Enhanced biohydrogen production from sewage sludge with alkaline pretreatment. Environ. Sci. Technol. 38, 3195-3202.

Chu, C.F., Ebie, Y., Xu, K.-Q., Li, Y.Y., Inamori, Y., 2010. Characterization of microbial community in the two-stage process for hydrogen and methane production from food waste. Int. J. Hydrogen Energy 35, 8253-8261. 
Cresson, R., Carrere, H., Delgenes, J.P., Bernet, N., 2006. Biofilm formation during the start-up period of an anaerobic biofilm reactor - Impact of nutrient complementation. Biochem. Eng. J. 30, 55-62.

Egues, I., Alriols, M.G., Herseczki, Z., Marton, G., Labidi, J., 2010. Hemicelluloses obtaining from rapeseed cake residue generated in the biodiesel production process. J. Ind. Eng. Chem. 16, 293-298.

Elefsiniotis, P., Wareham, D.G., Oldham, W.K., 1996. Particulate organic carbon solubilization in an acid-phase upflow anaerobic sludge blanket system. Environ. Sci. Technol. 30, 1508-1514.

Fox, P., Pohland, F.G., 1994. Anaerobic treatment applications and fundamentals-substrate-specificity during phase-separation. Water Environ. Res. 66, 716-724.

He, P.J., Shao, L.M., Qu, X., Li, G.J., Lee, D.J., 2005. Effects of feed solutions on refuse hydrolysis and landfill leachate characteristics. Chemosphere 59, 837-844.

Kaparaju, P., Serrano, M., Thomsen, A.B., Kongjan, P., Angelidaki, I., 2009. Bioethanol, biohydrogen and biogas production from wheat straw in a biorefinery concept. Bioresour. Technol. 100, 2562-2568.

Karakashev, D., Batstone, D.J., Angelidaki, I., 2005. Influence of environmental conditions on methanogenic compositions in anaerobic biogas reactors. Appl. Environ. Microbiol. 71, 331-338.

Kida, K., Morimura, S., Sonoda, Y., 1993. Accumulation of propionic-acid during anaerobic treatment of distillery wastewater from barley-shochu making. J. Ferment. Bioeng. 75, 213-216.

Kongjan, P., O-Thong, S., Kotay, M., Min, B., Angelidaki, I., 2010. Biohydrogen 
Production From Wheat Straw Hydrolysate by Dark Fermentation Using Extreme Thermophilic Mixed Culture. Biotechnol. Bioeng. 105, 899-908.

Kyazze, G., Dinsdale, R., Guwy, A.I., Hawkes, F.R., Premier, G.C., Hawkes, D.L., 2007. Performance characteristics of a two-stage dark fermentative system producing hydrogen and methane continuously. Biotechnol. Bioeng. 97, 759-770.

Liu, D.W., Liu, D.P., Zeng, R.J., Angelidaki, I., 2006. Hydrogen and methane production from household solid waste in the two-stage fermentation process. Water Res. 40, 2230-2236.

Luo, G., Talebnia, F., Karakashev, D., Xie, L., Zhou, Q., Angelidaki, I., 2010a. Enhanced bioenergy recovery from rapeseed plant in a biorefinery concept. Bioresour. Technol. In press (doi: 10.1016/j.biortech.2010.09.071)

Luo, G., Xie, L., Zou, Z.H., Wang, W., Zhou, Q., 2010b. Exploring optimal conditions for thermophilic fermentative hydrogen production from cassava stillage. Int. J. Hydrogen Energy 35, 6161-6169.

Nochur, S.V., Demain, A.L., Roberts, M.F., 1992. Carbohydrate utilization by Clostridium thermocellum: Importance of internal $\mathrm{pH}$ in regulating growth. Enzyme Microb. Technol. 14, 338-349.

O-Thong, S., Prasertsan, P., Karakashev, D., Angelidaki, I., 2008. Thermophilic fermentative hydrogen production by the newly isolated Thermoanaerobacterium thermosaccharolyticum PSU-2. Int. J. Hydrogen Energy 33, 1204-1214.

Schuppert, B., Schink, B., Trosch, W., 1992 Batch and continuous production of propionic acid from whey fermeate by Propionibacterium acidi-propionici in a three-electerode amperometric culture system. Appl. Microbiol. Biotechnol. 
7, 549-553.

Selembo, P.A., Perez, J.M., Lloyd, W.A., Logan, B.E., 2009. Enhanced hydrogen and 1,3-propanediol production from glycerol by fermentation using mixed cultures. Biotechnol. Bioeng. 104, 1098-1106.

Shin, S.G., Han, G., Lim, J., Lee, C., Hwang, S., 2010. A comprehensive microbial insight into two-stage anaerobic digestion of food waste-recycling wastewater. Water Res. In press (doi:10.1016/j.watres.2010.07.019)

Thamsiriroj, T., Murphy, J.D., 2010. Can Rape Seed Biodiesel Meet the European Union Sustainability Criteria for Biofuels? Energy Fuels 24, 1720-1730.

Ueno, Y., Fukui, H., Goto, M., 2007. Operation of a two-stage fermentation process producing hydrogen and methane from organic waste. Environ. Sci. Technol. 41, 1413-1419.

Van lier, J.B., Grolle, K.C.F., Frijters, C., Stams, A.J.M., Lettinga, G., 1993. Effects of acetate, propionate, and butyrate on the thermophilic anaerobic degradation of propionate by methanogenic sludge and defined cultures. Appl. Environ. Microbiol. 59, 1003-1011.

Venetsaneas, N., Antonopoulou, G., Stamatelatou, K., Kornaros, M., Lyberatos, G., 2009. Using cheese whey for hydrogen and methane generation in a two-stage continuous process with alternative $\mathrm{pH}$ controlling approaches. Bioresour. Technol. 100, 3713-3717.

Wiegant, W.M., Claassen, J.A., Lettinga, G., 1985. Thermophilic anaerobic -digestion of high-strength wastewaters. Biotechnol. Bioeng. 27, 1374-1381.

Xie, B.F., Cheng, J., Zhou, J.H., Song, W.L., Liu, J.Z., Cen, K.F., 2008. Production of hydrogen and methane from potatoes by two-phase anaerobic fermentation. Bioresour. Technol. 99, 5942-5946. 
510 Zhao, C.X., O-Thong, S., Karakashev, D., Angelidaki, I., Lu, W.J., Wang, H.T., 2009. High yield simultaneous hydrogen and ethanol production under extreme-thermophilic (70 degrees C) mixed culture environment. Int. J. Hydrogen Energy 34, 5657-5665.

Zhu, H., Stadnyk, A., Béland M., Seto, P., 2008. Co-production of hydrogen and methane from potato waste using a two-stage anaerobic digestion process. Bioresour. Technol. 99, 5078-5084. 


\section{Figure caption:}

518 Fig 1 Profiles of methane production, $\mathrm{pH}$ and VFA of single-stage process (M15)

519 Fig 2 Profiles of gas production, $\mathrm{pH}$ and VFA in hydrogen reactor (A, B) and methane 520 reactor (C, D) of two-stage process (H3+M12)

521 Fig 3 Profiles of gas production, $\mathrm{pH}$ and VFA in hydrogen reactor (A, B) and methane 522 reactor $(\mathrm{C}, \mathrm{D})$ of two-stage process $(\mathrm{H} 1+\mathrm{M} 14)$ Fig 4 DGGE bands of bacterial communities. A, H3 (stillage); B, M12 (stillage); C,

524 M15 (stillage); D, H3 (mixture); E, M12 (mixture); F, H1 (mixture); G, M14 525 (Mixture). 


\begin{tabular}{lllll}
\hline & Stillage & Cake & Glycerol & Mixture \\
\hline $\mathrm{pH}$ & $3.9 \pm 0.1$ & $/$ & $7 \pm 0.1$ & $4.2 \pm 0.1$ \\
$\mathrm{TS}(\%)$ & $4.75 \pm 0.15$ & $85.6 \pm 1.55$ & $/$ & $6.85 \pm 0.05$ \\
VS (\%) & $4.5 \pm 0.11$ & $79.6 \pm 1.28$ & $/$ & $6.82 \pm 0.03$ \\
COD (g/L) & $61.9 \pm 1.8$ & $/$ & $1638 \pm 103$ & $97.3 \pm 2.1$ \\
SCOD (g/L) & $20.8 \pm 1.9$ & $/$ & $/$ & $29.8 \pm 1.2$ \\
VFA (g/L) & $0.15 \pm 0.08$ & $/$ & $/$ & $0.08 \pm 0.01$ \\
TSS(g/L) & $35.4 \pm 1.2$ & $/$ & $/$ & $54.8 \pm 1.3$ \\
VSS(g/L) & $34 \pm 1.6$ & $/$ & $/$ & $54 \pm 2.1$ \\
Total nitrogen (g/L) & $1.44 \pm 0.06$ & $30.6 \pm 0.85^{\mathrm{a}}$ & $0.23 \pm 0.01$ & $2.16 \pm 0.05$ \\
Ammonia (g/L) & $0.27 \pm 0.05$ & $1.4 \pm 0.05^{\mathrm{a}}$ & $\mathrm{N} . \mathrm{D}$ & $0.27 \pm 0.03$ \\
Carbohydrate (g/L) & 30 & $580^{\mathrm{a}}$ & $/$ & 48.9 \\
Lipid (g/L) & $7.5 \pm 1.2$ & $35 \pm 1.2^{\mathrm{a}}$ & $51 \pm 2.5$ & $8 \pm 0.6$ \\
Protein (g/L) & $7.2 \pm 0.8$ & $181 \pm 5.02^{\mathrm{a}}$ & $1.42 \pm 0.03$ & $11.3 \pm 0.8$ \\
\hline
\end{tabular}


Table 2 Reactor operation data

\begin{tabular}{|c|c|c|c|c|c|}
\hline \multirow[t]{2}{*}{ Parameter } & \multirow{2}{*}{$\begin{array}{l}\text { Single-stage } \\
\text { M15 }\end{array}$} & \multicolumn{2}{|c|}{ Two-stage } & \multicolumn{2}{|c|}{ Two-stage } \\
\hline & & H3 & M12 & H1 & M14 \\
\hline HRT & 15 & 3 & 12 & 1 & 14 \\
\hline $\begin{array}{l}\text { working volume, } \\
\text { L }\end{array}$ & 3.5 & 1.2 & 3.5 & 1.2 & 3.5 \\
\hline feed rate, mL/d & 233 & 400 & 292 & 1200 & 250 \\
\hline
\end{tabular}


Table 3 Summary of reactor performances at steady-states

\begin{tabular}{lllll}
\hline & One-stage & Two-stage & Two-stage & Two-stage \\
\hline Substrate & Stillage & Stillage & Mixture & Mixture \\
& & & & \\
Hydrogen reactor & & H3 & H3 & H1 \\
HRT(d) & $/$ & 3 & 3 & 1 \\
Hydrogen yield (ml/gVS) & $/$ & $69 \pm 6.3$ & $48 \pm 5.5$ & $40 \pm 4.7$ \\
pH & $/$ & $5.2 \pm 0.1$ & $5.2 \pm 0.1$ & $5.3 \pm 0.1$ \\
Ethanol (mM) & $/$ & $17.7 \pm 0.8$ & $18.6 \pm 1.2$ & $10.1 \pm 1.2$ \\
Acetate (mM) & $/$ & $22.1 \pm 1.8$ & $22.8 \pm 1.3$ & $17.7 \pm 1.3$ \\
Propionate (mM) & $/$ & $0.7 \pm 0.2$ & $0.3 \pm 0.1$ & $0.4 \pm 0.1$ \\
Butyrate (mM) & $/$ & $63.7 \pm 2.0$ & $64.8 \pm 2.4$ & $53.7 \pm 1.4$ \\
Valerate (mM) & $/$ & $0.2 \pm 0.1$ & $0.1 \pm 0.1$ & $0.2 \pm 0.1$ \\
SCOD (g/L) & $/$ & $23.5 \pm 2.2$ & $33.6 \pm 3.4$ & $32.5 \pm 2.8$ \\
TCOD (g/L) & $/$ & $57.5 \pm 4.7$ & $92.6 \pm 7.6$ & $93.8 \pm 5.9$ \\
NH ${ }_{3}-\mathrm{N}(\mathrm{mg} / \mathrm{L})$ & $/$ & $310 \pm 50$ & $360 \pm 75$ & $350 \pm 62$ \\
VSS (g/L) & $/$ & $29 \pm 1.8$ & $47.7 \pm 3.1$ & $51.5 \pm 2.6$ \\
Energy (KJ/gVS) & $/$ & $0.7 \pm 0.07$ & $0.5 \pm 0.06$ & $0.4 \pm 0.05$ \\
& & & & \\
Methane reactor & $11.8 \pm 0.49$ & $12.4 \pm 0.51$ & $11.4 \pm 0.52$ & $12.3 \pm 0.69$ \\
HRT & & & & \\
Methane yield (ml/gVS) & $329 \pm 13.7$ & $348 \pm 14.2$ & $320 \pm 14.5$ & $344 \pm 19.5$ \\
pH & $7.8 \pm 0.1$ & $8.0 \pm 0.1$ & $7.9 \pm 0.1$ & $8.0 \pm 0.1$ \\
Ethanol(mM) & $0.2 \pm 0.1$ & $0.3 \pm 0.1$ & $0.1 \pm 0.1$ & $0.1 \pm 0.1$ \\
Acetate(mM) & $5.1 \pm 0.3$ & $6.3 \pm 0.3$ & $19.3 \pm 1.7$ & $8.7 \pm 0.7$ \\
Propionate(mM) & $36.4 \pm 1.6$ & $31.5 \pm 2.3$ & $28.5 \pm 1.2$ & $28.9 \pm 1.6$ \\
Butyrate(mM) & $1.6 \pm 0.3$ & $1.5 \pm 0.2$ & $4.6 \pm 0.6$ & $3.3 \pm 0.5$ \\
Valerate(mM) & $1.5 \pm 0.2$ & $7.5 \pm 0.4$ & $4.7 \pm 0.2$ & $4.3 \pm 0.5$ \\
SCOD(g/L) & $13.5 \pm 2.1$ & $8.3 \pm 1.5$ & $12.5 \pm 2.8$ & $11.3 \pm 1.8$ \\
TCOD(g/L) & $21.6 \pm 1.8$ & $16.2 \pm 3.2$ & $35.2 \pm 3.3$ & $29.5 \pm 2.1$ \\
NHH ${ }^{+}$-N(mg/L) & $1158 \pm 320$ & $1135 \pm 110$ & $1432 \pm 250$ & $1590 \pm 370$ \\
VSS(g/L) & $8 \pm 1.8$ & $8.6 \pm 2.3$ & $19.5 \pm 1.5$ & $18.5 \pm 1.9$ \\
Energy (KJ/gVS) & 15.49 & $13.1 \pm 0.55$ & $11.9 \pm 0.53$ & $12.7 \pm 0.72$ \\
\hline & & & &
\end{tabular}


Table 4 SMA of sludge biomass from methane reactors $\left(\mathrm{ml}-\mathrm{CH}_{4} /(\mathrm{gVS} \cdot \mathrm{d})\right.$ )

\begin{tabular}{lllll}
\hline Substrate & $\begin{array}{l}\text { Single-stage } \\
\text { (Stillage, M15) }\end{array}$ & $\begin{array}{l}\text { Two-stage } \\
\text { ( Stillage, } \\
\text { H3+M12) }\end{array}$ & $\begin{array}{l}\text { Two-stage } \\
\text { ( Mixture, } \\
\text { H3+M12) }\end{array}$ & $\begin{array}{l}\text { Two-stage } \\
\text { ( Mixture, } \\
\text { H1+M14) }\end{array}$ \\
\hline Glucose & $57.7 \pm 1.6$ & $72.2 \pm 1.1$ & $64.6 \pm 4.0$ & $70 \pm 3.5$ \\
Acetate & $45.3 \pm 2.0$ & $55.1 \pm 3.8$ & $63.1 \pm 2.9$ & $72 \pm 4.6$ \\
Propionate & $6.7 \pm 0.9$ & $5.7 \pm 2.5$ & $8.8 \pm 3.3$ & $6.1 \pm 2.8$ \\
Butyrate & $31.5 \pm 2.0$ & $45.5 \pm 1.9$ & $46.1 \pm 1.7$ & $41 \pm 3.2$ \\
Hydrogen & $28.8 \pm 2.2$ & $22.4 \pm 5.7$ & $24.3 \pm 2.7$ & $27 \pm 2.5$ \\
\hline
\end{tabular}


Table 5 DGGE 16S rRNA gene band identifications

\begin{tabular}{|c|c|c|c|c|}
\hline $\begin{array}{l}\text { DGGE } \\
\text { band }\end{array}$ & Closest match & Identity(\%) & Phyla & Accession no. \\
\hline \multicolumn{5}{|l|}{ Bacteria } \\
\hline & Uncultured gamma proteobacterium & 96 & Proteobacteria & HQ219810 \\
\hline & Uncultured Pseudomonas sp. & 95 & Proteobacteria & HQ219811 \\
\hline & Propionibacterium $s p$. & 97 & Actinobacteria & HQ219812 \\
\hline & Uncultured bacterium & 93 & Unaffiliate & HQ219813 \\
\hline & Streptococcus thermophilus & 93 & Firmicutes & HQ219814 \\
\hline & Uncultured bacterium & 96 & Unaffiliate & HQ219815 \\
\hline & Clostridium sp. & 94 & Firmicutes & HQ219816 \\
\hline & Thermoanaerobacterium thermosaccharolyticum & 100 & Firmicutes & HQ219817 \\
\hline & Thermoanaerobacterium thermosaccharolyticum & 95 & Firmicutes & HQ219818 \\
\hline 1 & Clostridium thermocellum & 98 & Firmicutes & HQ219819 \\
\hline 1 & Thermoanaerobacterium sp. & 100 & Firmicutes & HQ219820 \\
\hline \multicolumn{5}{|l|}{ Archaea } \\
\hline & Methanoculleus thermophilus & 96 & Euryarchaeota & HQ219821 \\
\hline & Methanoculleus thermophilus & 97 & Euryarchaeota & HQ219822 \\
\hline & Methanosarcina acetivorans str. & 96 & Euryarchaeota & HQ219823 \\
\hline & Methanosarcina barkeri & 94 & Euryarchaeota & HQ219824 \\
\hline
\end{tabular}



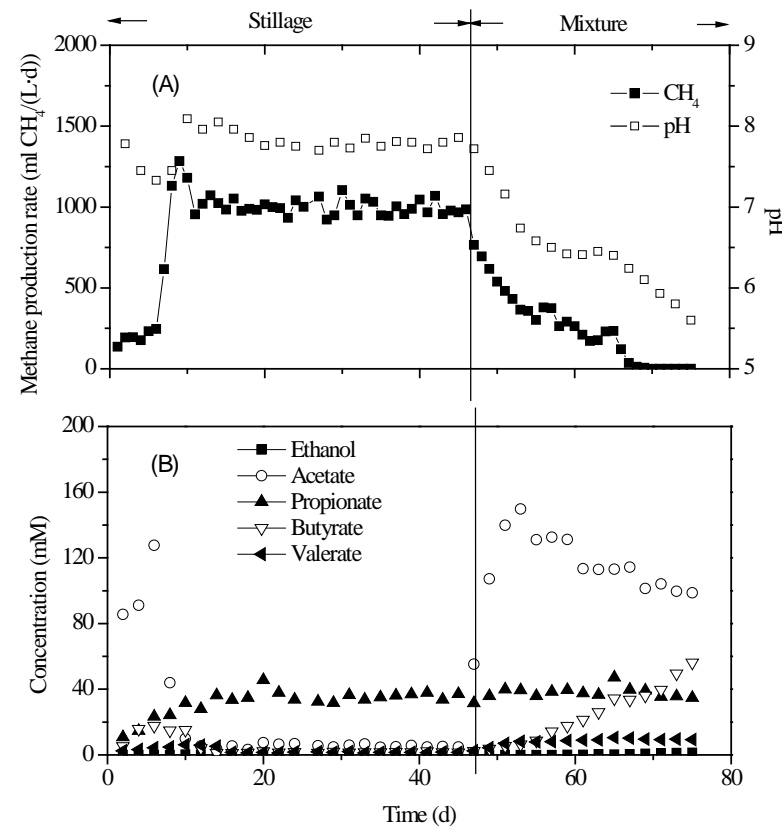

Fig 1 Profiles of methane production, $\mathrm{pH}$ and VFA of single-stage process (M15) 

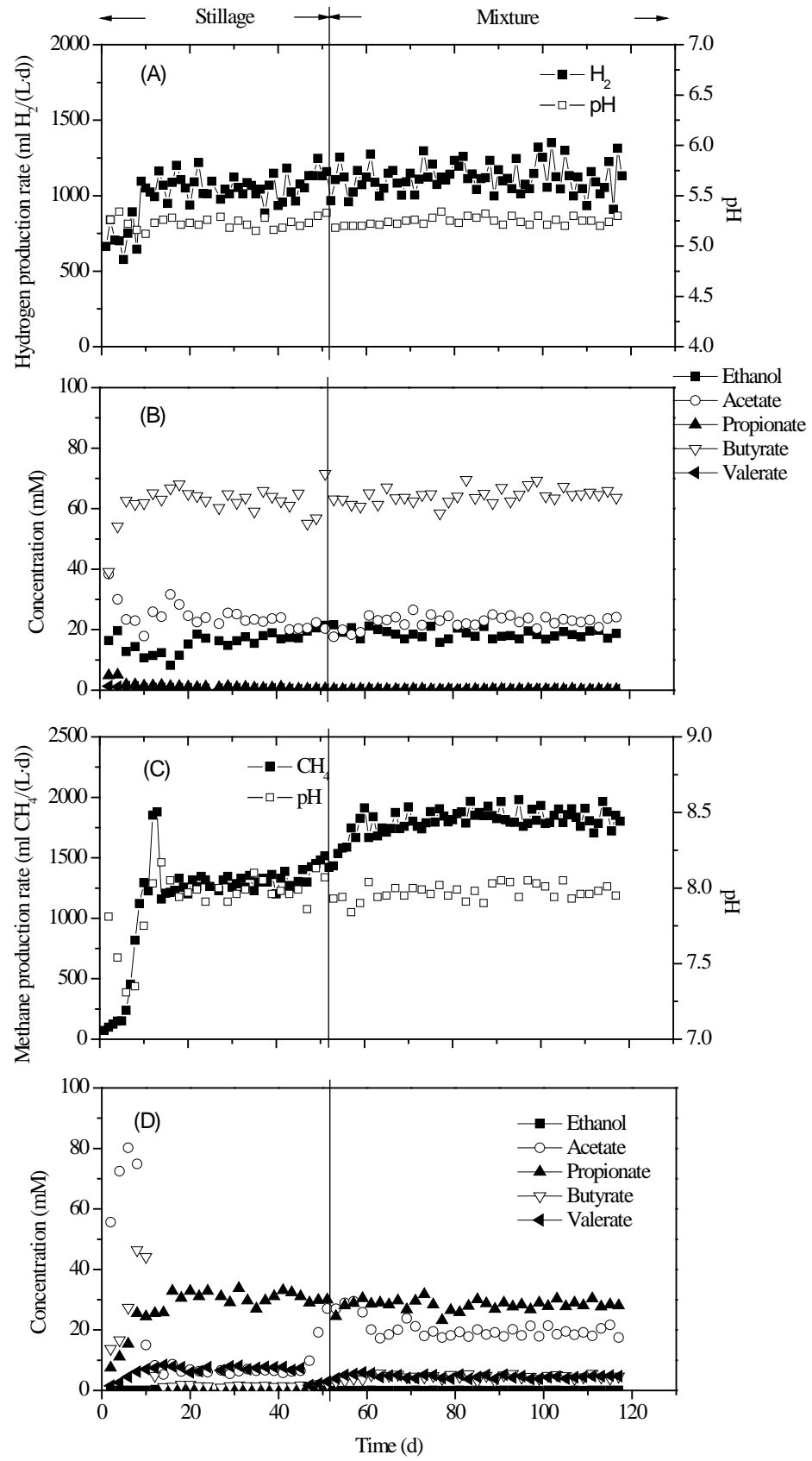

Fig 2 Profiles of gas production, $\mathrm{pH}$ and VFA in hydrogen reactor (A, B) and methane reactor $(\mathrm{C}, \mathrm{D})$ of two-stage process $(\mathrm{H} 3+\mathrm{M} 12)$ 

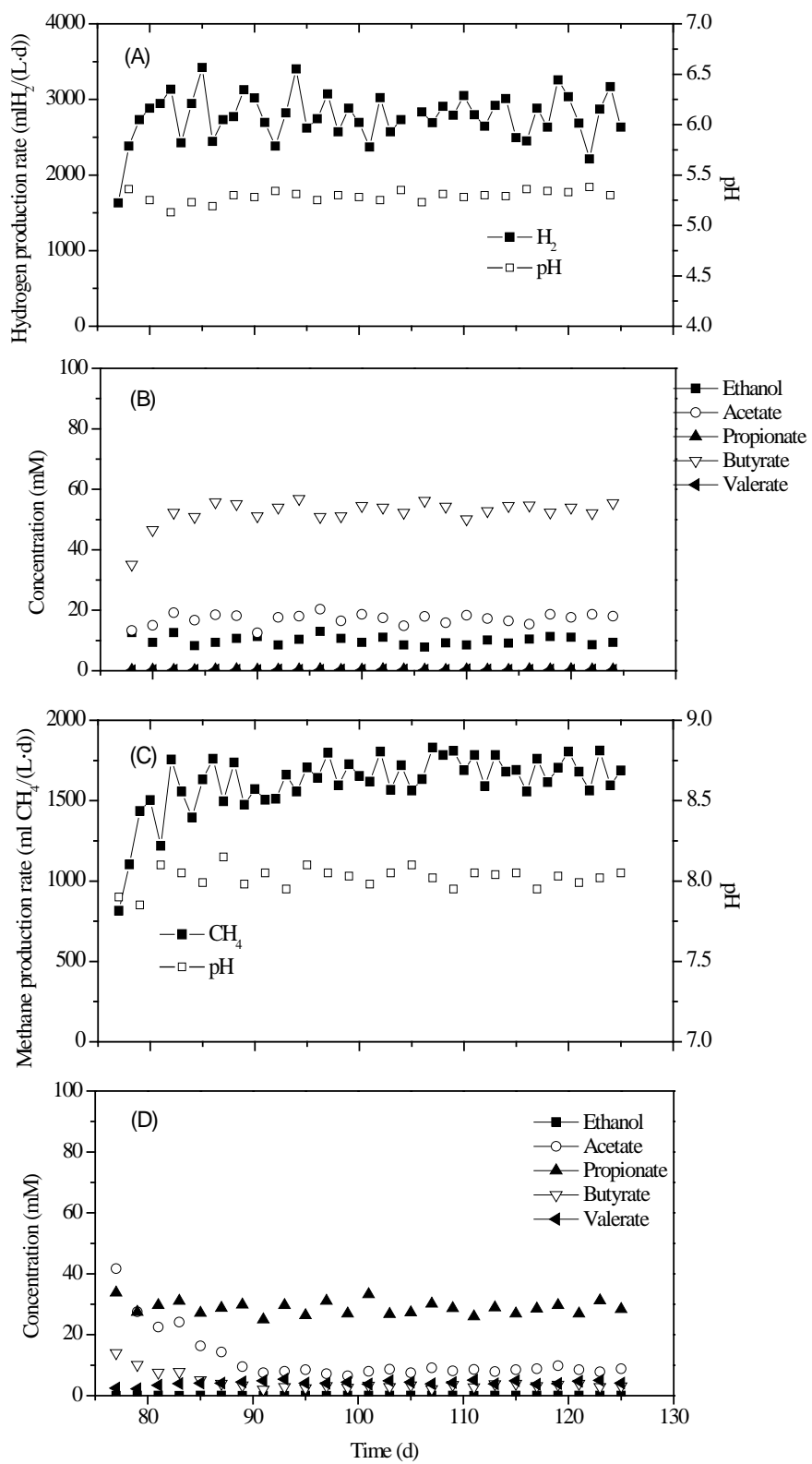

Fig 3 Profiles of gas production, pH and VFA in hydrogen reactor (A, B) and methane reactor (C, D) of two-stage process (H1+M14) 


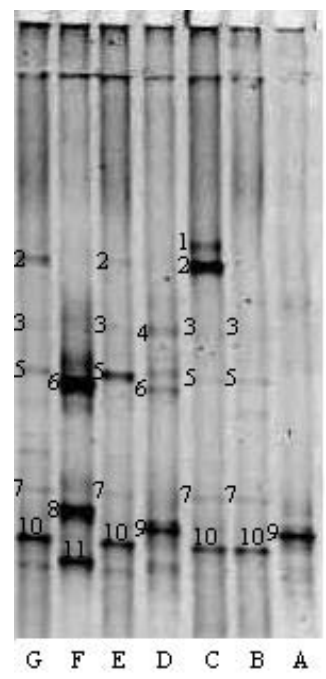

Fig 4 DGGE bands of bacterial communities. A, H3 (stillage); B, M12 (stillage); C, M15 (stillage); D, H3 (mixture); E, M12 (mixture); F, H1 (mixture); G, M14 (Mixture). 


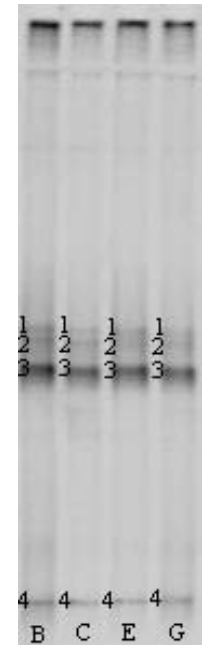

Fig 5 DGGE bands of archaeal communities. 